Equilibrium Res Suppl. 1, 1971

\title{
NEUROTOLOGICAL STUDIES ON VLRTIGO DUE TO WHIPLASH INJURY
}

\author{
Manabi Hinoki, Sonoji HINE and Yutaka TADA*
}

To see whether hypertension of the cervical musculature participates in producing vertigo due to a whiplash injury of the neck, we developed two types of equilibrium tes:s: equilibrium tes:s involving anodic low-frequency pulse stimulation of the neck and equilibrium tests performed after fixing the neck with a collar. Disequilibrium due to the whiplash injury was often aggravated by pulse stimulation, whereas it tended to decrease or disappear on fixing the neck with a collar. These findings indicate that hypertension of the cervical soft tissues is often an important factor in the development of verigo due to whiplash injury.

To investigate the possible existence of hypothalamo-brain stem dysfunction in vertigo cases with whiplash injury, we carried out equilibrium tests with adrenaline loading. These tests showed that in most cases with vertigo, ataxia appeared or was intensified by adrenaline loading. We concluded that hypothalamo-brain stem dysfunction is a possible etiologic factor in the development of vertigo due to whiplash injury.

According to these observations, veriigo due to whiplash injury seems to develop because abnormal centripetal impulses arising from the injured cervical soft tissues reach the hypothalamo-brain stem and cause manifestation of dysfunction of these parts of the brain. Thus, marked ataxia of the eyes, the trunk and the limbs might results, leading to vertigo in these cases. This conclusion is supported by our previous observations of the electroencephalograms of rabbits, where functional disorders of the cervical muscles, especially the deep group of nuzhal mussles, produced functional disturbances of the brain sten reticular formation. Therefore, treatment for this kind of vertigo should be dirested to improve impuired function both (I) in the cervical region and (II) in the hypothalamo-brain stem. Reasonable methods for (I) include cathodic low-frequency pulse stimulation of tender spots on the neck, procaine infiltration in 0 painful areas of the cervical soft tissues, and paraffine packing around the neck and shoulder. In our clinical experience, rest and support were the best measures for success in the first 10 to 14 days after trauma. Therefore, soon after the injury, traction of the neck should be avoided. Methods for (II) include administration of p-chlorophenoxyacetic dimethyl aminoethyl ester (Lucidril or Centrophenoxine) or C.D.P.-choline (Nicholin), known to ameliorate dysfunction of the hypothalamo-brain stem. These methods were found helpful in relieving symptoms, especially vertigo.

From the Department of Otolaryngology, School of Medicine, Tokushima University, Tokushima

* From the Department of Otolaryngology, Tokushima Municipal Hospital, Tokushima 


\section{INTRODUCTION}

The following three theories on the etiology of cervical vertigo have been proposed and widely believed: 1. The theory of cervical sympathetic nerve irritation (Barré ${ }^{2}$ 1926, Lieou $^{27}$ 1928, Maspetiol ${ }^{30}$ 1960); 2. The theory of abnormal neck reflex (Campbell and Parsons $^{10}$ 1944, Weeks and Travel $l^{46} 1955$, Gray ${ }^{13}$ 1956, Cope and Ryan ${ }^{11} 1959$, Ishii et al. ${ }^{23}$ 1962, Hinoki and Kurosawa ${ }^{17}$ 1964, Hinoki et al. ${ }^{20}$ 1967, Hinoki ${ }^{15}$ 1967) and 3. The theory of mechanical compression or stenosis of the vertebral artery (De Kleyn ${ }^{25} 1933$, Bärtshi-Rochaix ${ }^{3}$ 1948, Biemond ${ }^{4}$ 1951, Tissington-Tatlow and Bammer ${ }^{42}$ 1957, Schneider and Crosby ${ }^{38} 1959$, Sandström ${ }^{37}$ 1961). All these theories are well supported clinically and experimentally, so we must consider multiple mechanisms in the etiology of cervical vertigo. However, from our clinical and experimental experience, the second theory is of particular interest.

The cervical spine consists of a series of vertebrae. On the top of these vertebrae rests a heavy object, the head, articulating with the atlas by two joints. Whiplash injury results from sudden jerking of the head either forward, backward, or from one side to the other, without a blow on the head from a solid object. Therefore, when whiplash mechanisms occur in the cervical spine, soft tissues supporting the cervical vertebrae may be injured, resulting in functional or even organic damage of these tissues. Recent investigations revealed that when animals, such as monkeys or rabbits, received whiplash injuries experimentally, they often showed lesions of the cervical soft tissues indicated by haemorrhage, swelling, and even rupture of the musculoligaments (Ikeda and Kobayashi ${ }^{21}$ 1967). In human subjects, essentially similar lesions of the cervical soft tissues could be produced by a whiplash mechanism; although this has not been clarified in detail because patients suffering from whiplash trauma often show abnormal EMG discharges in the neck region. Furthermore, in our clinical experience these discharges were closely related to the subject's complaints, particularly pain in the neck and vertigo, throughout the course of treatment. These findings suggest that hypertension of the cervical soft tissues may be an etiological factor in producing vertigo due to whiplash injury. The present investigation was performed to test this theory.

\section{EXPERIMENTAL}

(A) Complaints of subjects with whiplash injury

The following 4 items were examined in 70 traumatized patients aged 15 to $60: 1$. History, especially present illness and chief complaints; 2 . Equilibrium and cochlear functions; 3. Neurological state including EEG and EMG; and 4. X-ray photos of the neck. The period after an accident had taken place before the cases were examined varied from as little as 1 hour to as much as 2 years. Table 1 shows symptoms of cases due to whiplash injury. To simplify study of symptoms caused by whiplash trauma, all cases in which the head struck a solid object are omitted. Most symptoms were caused by motor accidents, especially bumps from behind. As shown in Table 1, the most com-

Equilibrium Res Suppl. 1 
Table 1. Frequency of complaints by patients with whiplash injury (70 cases)

\begin{tabular}{lcc}
\hline & Number of cases & Incidence (\%) \\
\hline Stiffness of the neck & 65 & 93 \\
Head dullness & 64 & 91 \\
Vertigo & 60 & 86 \\
Headache & 59 & 84 \\
Nuchal pains & 47 & 67 \\
Numbness of the limbs & 39 & 56 \\
Nausea, Vomiting & 39 & 56 \\
Emotional instability & 38 & 54 \\
Lumbar pains & 33 & 47 \\
Insomnia & 29 & 41 \\
Loss of physical and mental efficiency & 28 & 40 \\
Oppression of the chest, palpitation & 27 & 39 \\
Lachrymation & 20 & 29 \\
Decrease of body weight & 20 & 29 \\
Tinnitus & 16 & 23 \\
Abnormal sweating & 16 & 23 \\
Deafness & 12 & 17 \\
Smell disturbance & 8 & 11 \\
\hline
\end{tabular}

mon were vertigo together with headache and tenderness of the neck, although the symptoms varied. The vertigo seen in most of our traumatized patients was nonrotatory, and it was not always accompanied by cochlear symptoms. This is in contrast to the well known fact that vertigo cuased by peripheral labyrinthine disturbances is usually rotatory and is accompanied by cochlear symptoms. Furthermore, as previously stated, vertigo in our traumatized patients was observed parallel with tenderness of the neck throughout treatment, indicating hypertension of the cervical soft tissues; that is, among our clinical cases, of the 15 vertigo cases in which tenderness of the neck disappeared during the observation period, 11 cases $(73 \%)$ showed reduction of vertigo. Whereas, of the 7 vertigo cases in which cervical pain increased, 5 cases $(77 \%)$ showed aggravation of vertigo as well. These facts suggest that functional disturbances of the cervical soft tissues, such as muscles, ligaments, joint capsules and sensory nerves, may be important etiological factors in producing vertigo due to whiplash injury. This was examined in the experiments described below.

(B) Equilibrium tests with anodic low-frequency pulse stimulation of the neck

(1) Method: To test the validity of the hypothesis that hypertension of the cervical soft tissues is a factor in producing vertigo due to whiplash mechanism, it is necessary to see whether the appearance or intensification of ataxia occurs in cases where tonus of the cervical soft tissues increases. One method used for examining cervical vertigo is to load the cervical region in a certain way and study the consequent changes in eye and body equilibrium (Bos ${ }^{5}$ 1962, Philipszoon ${ }^{34}$ 1962, Tokita ${ }^{43}$ 1965). For instance, Tokita examined cases of Meniere's disease, both by the nystagmus test and the blindfolded verti- 
cal writing test, for possible disturbances of equilibrium on right or left rotation of the head, trying in this way to demonstrate the existence of a cervical factor in Meniere's disease (Tokita ${ }^{43}$ 1965). His method is superior to the ordinary one; but by using it, it is impossible to decide whether the impaired equilibrium observed is chiefly due to stenosis of the vertebral artery caused by head rotation or to increased abnormal centripetal impulses arising from the injured cervical soft tissues. According to Suzuki, application for a certain period of anodic low-frequency pulse stimulation causes an increase in excitability of the muscle or nerve underlying the electrode (Suzuki ${ }^{40}$ 1955). Thus, when a certain anodic low-frequency pulse stimulation is applied to the patient's nuchal soft tissues, which have enhanced irritability, abnormal centripetal impulses from them should increase and result in the appearance or intensification of ataxia of the eyes and body. Accordingly, we applied anodic. low-frequency pulse stimulation at $25 \mathrm{~Hz}, 0.4-1.0 \mathrm{~mA}$, and 5-6v for 10 minutes to tender spots in the nuchal region at the level of the second or third cervical vertebra, and measured the resulting changes in eye and body equilibrium by testing the arm drift reaction (the blindfolded vertical writing test) and tests of oculomotor function (the optic eye nystagmus test and the eye tracking test). Observations were made prior to stimulation and 10 minutes after starting the stimulation.

(2) Results

(i) Results obtained in normal subjects: Thirty normal subjects examined by these tests showed neither vertigo nor the appearance of ataxia of the eyes and body.

(ii) Results obtained in vertigo cases with whiplash injury

(a) Representative cases

Case 1: A 49 year old man who sustained a whiplash injury when his car was bumped from the rear. At the time of the accident he lost consciousness for about 3 minutes. Four days later a sensation of swaying of the body developed associated with pain and

The optic eye nystagmus test on anodic low-frequency pulse stimulation of the neck Before stimulation

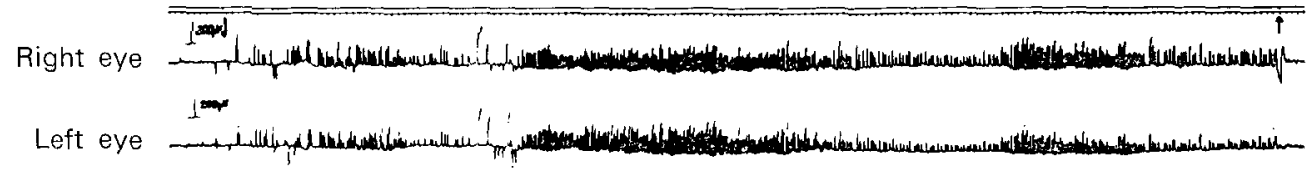

10 minutes after starting the stimulation

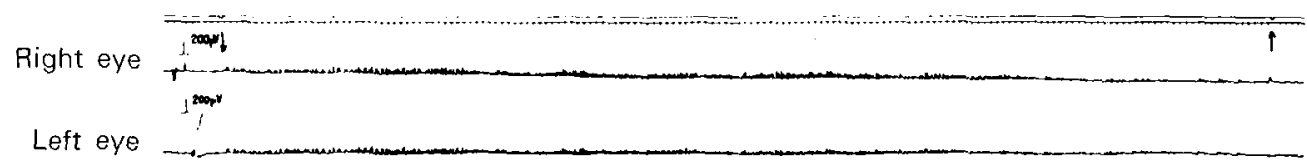

Fig. 1. Shows optic eye nystagmus of a 49 year old man with whiplash injury. Before anodic low-frequency pulse stimulation optic eye nystagmus shows abnormal reactivity with a mixture of hypo-, and hyperactive eye nystagmus. Ten minutes after starting pulse stimulation optic eye nystagmus became reduced in frequency and eye speed, supporting the subject's complaint of increase in vertigo. 
stiffness of the neck, bilateral tinnitus, deafness and vomiting. Lateral X-rays of the neck revealed a moderate incongruence of the vertebrae at the level of $c_{4,5}$ as well as loss of the normal cervical curve. He complained of an increased swaying sensation and difficulty in following the horizontal movements of vertical stripes of light when anodic low-frequency pulse stimulation was applied to tender spots of the right nuchal tissues. As shown in Fig. 1, optic nystagmus before pulse stimulation showed abnormal reactivity with a mixture of hypo-, and hyperactive eye nystagmus. Ten minutes after pulse stimulation optic eye nystagmus became reduced in frequency and eye speed, supporting the subject's complaint of increase in vertigo.

Case 2: A 42 year old man sustained a whiplash injury when his car was struck by a vehicle one month previous to examination. Immediately after the impact he was dazed for 10 minutes. One hour after the accident he developed pain of the left side of the neck and swaying sensation of the body accompanied by black-out in standing up. These

Ocular movements in the eye tracking test on anodic low-frequency pulse stimulation of the neck

Before stimulation

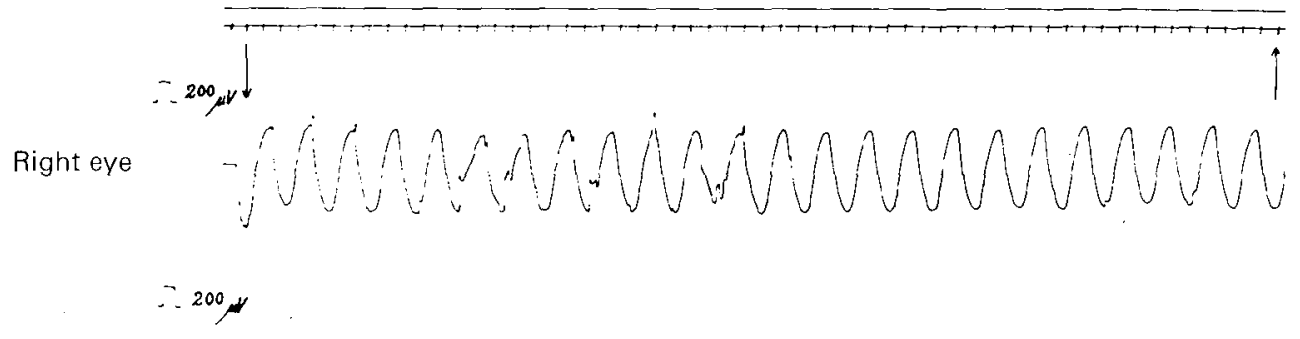

Left eye

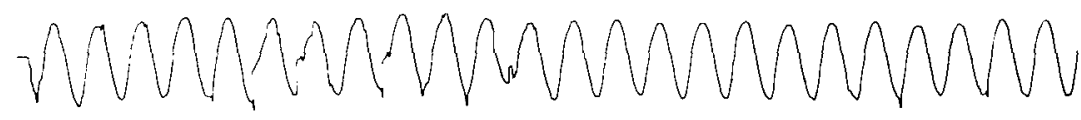

10 minutes after starting the stimulation

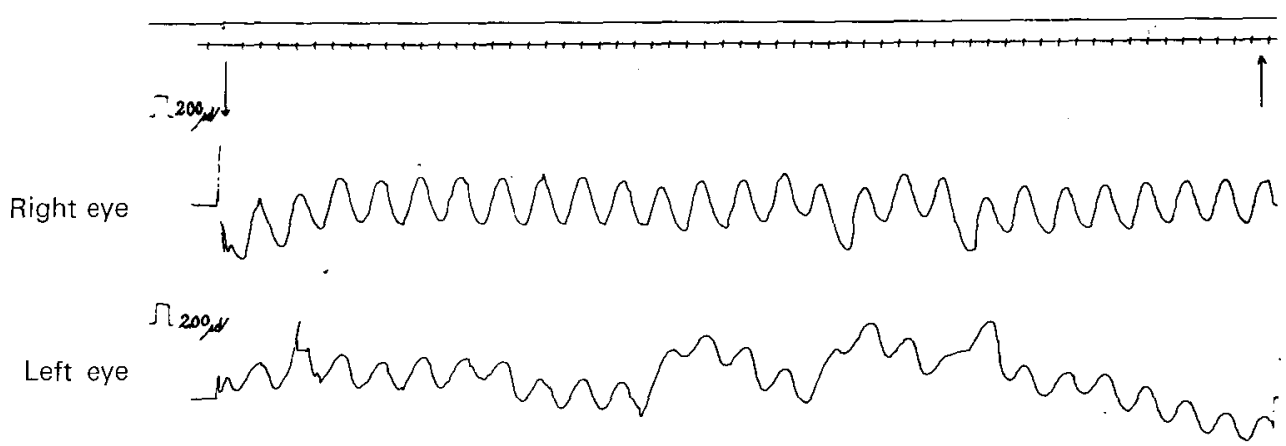

Fig. 2. Shows eye tracking curves of a 42 year old man who sustained a whiplash injury. Eye tracking curves before anodic low-frequency pulse stimulation are almost normal except for. the occurrence of a few zigzag curves. Ten minutes after starting pulse stimulation, eye tracking function deteriorates greatly, with irregular movements of both eyes, especially the left. as shown in the lower part of this figure. 
complaints are still present and are associated with changes in the weather. Lateral Xrays of the neck revealed an incongruence of vertebrae at the level of $c_{3,4}$, which increased in degree on extreme forward flextion of the head. He complained of an increased sensation of swaying and inability to follow a moving object (a target) when a low-frequency pulse stimulation was applied. As shown in Fig. 2, these complaints were accompanied by aggravation of eye tracking function where irregular curves, especially those of the left eye, were noted.

(b) Results obtained in 46 vertigo cases with whiplash injury

When at least one of the following 3 items was induced from the equilibrium tests mentioned above, the result was taken as positive: 1 . The appearance or intensification of deviation in writing, or ataxic writing; 2 . Marked inhibition or abnormal facilitation of optic eye nystagmus or the appearance of abnormal optic eye nystagmus as indicated by the inversion phenomenon; and 3. The appearance or intensification of abnormal eye tracking curves as indicated by zigzag, stepwise or irregular curves. Positive results were obtained in $26(56.6 \%)$ of the 46 cases examined. Of the remaining 20 cases, 17 showed no demonstrable changes in pre-existing ataxia and 3 showed alleviation thereof. Incidentally, ataxia seen in vertigo cases with whiplash injury tended to become reduced when painful spots of the neck were blocked by procaine infiltration. Furthermore, after the latter treatment, anodic low-frequency pulse stimulation of the neck did not induce intensification of ataxia. These findings suggest that hypertension of the cervical soft tissues after a whiplash injury is a major factor in producing vertigo.

(C) Equilibrium tests after fixing the neck with a collar

(1) Method: To obtain further evidence of whether hypertension of the cervical soft tissues is a major factor in the development of vertigo due to whiplash injury, Usio, one of our co-workers, designed equilibrium tests in which the patient's neck was fixed with a collar. These tests were conceived from the fact that when the neck of a patient suffering from vertigo and nuchal pain was fixed with a collar, not only the nuchal pain, but also the sensation of unsteadiness of the body were reduced. Furthermore, on fixing the collar, the abnormal EMG discharges from the tender areas of the neck and the preexisting ataxia of the body tended to be reduced. These findings suggested that this procedure could be employed as a new technique to study the etiology of cervical vertigo. In this type of equilibrium test, the neck of the subjects was fixed with a plastic collar (polyneck), and changes in eye and body equilibrium functions were measured by tests of the righting reflex (Romberg test and Mann's test), test of the arm drift reaction (the blindfolded vertical writing test), and tests of oculomotor function (the optic eye nystagmus test and the eye tracking test). Observations were made before and after neck fixation.

(2) Results

(i) Results obtained in vertigo cases with whiplash injury; Representative cases:

Case 3: A 47 year old man sustained a whiplash injury when his car was bumped from the rear at a crossing while he was waiting for the light to change. Immediately after the impact he lost consciousness for about 3 minutes. Within a few hours after the injury 
unsteadiness of the body developed, associated with headache, nuchal pain, stiffness of the shoulders and slight numbness of the upper limbs. Six months after the accident numbness of the upper limbs has disappeared, but the other symptoms are still present. In

Righting reflex in a case of neck fixation with a collar

-Recordings of cephalograms and electromyograms in a case of Mann's test-Without a collar

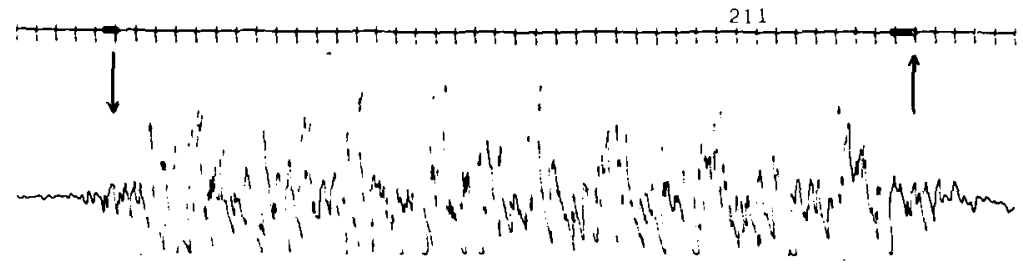

EMG (R. neck)

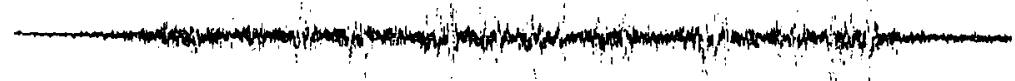

$\operatorname{EMG}($ L. neck)

With a collar
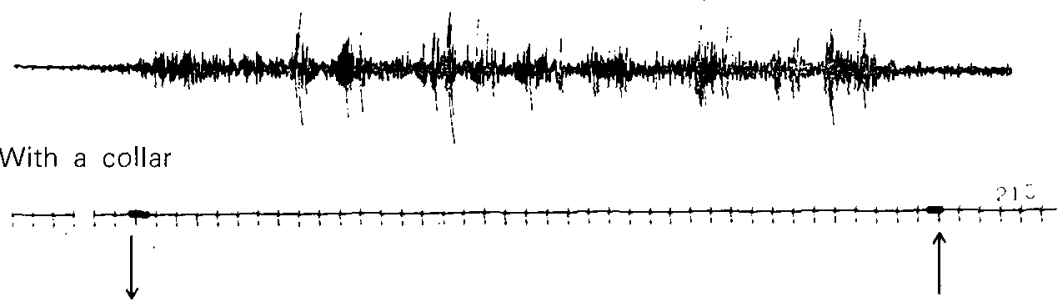

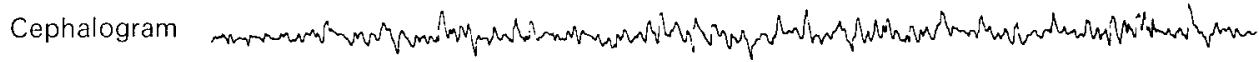

$\operatorname{EMG}($ R. neck)

EMG (L. neck)

Fig. 3. Shows cephalograms and EMG's from the nuchal regions of a 47 year old man with whiplash injury. At the top of the figure the cephalogram is shown and the two lower rows show the EMG's of the right and left nuchal muscles in each figure. Swaying of the head and abnormal EMG discharges from the nuchal muscles apparently appear when no collar is worn. This tendency is greatly reduced on fixing the neck, indicating a demonstrable reduction in swaying of the head and abnormal EMG discharges.

Equilibrium Res Suppl. I 
addition to these symptoms, he recently developed photophobia and lachrymation. Lateral X-rays revealed an incongruence of the cervical vertebrae at the level of $c_{3,4}$. Extension and flexion of the head were limited because of nuchal pain. When his neck was fixed with a plastic collar, the pain in the neck and feeling of unsteadiness were greatly reduced. Fig. 3 shows the cephalogram recorded with a strain-gage-type instrument and the EMG's from tender spots of the right and left nuchal regions. As shown in this figure, swaying of the head and abnormal EMG discharges.from the nuchal regions were much reduced when the neck was fixed. It should be noted here that the incongruence mentioned above was apparently corrected by the collar.

The optic eye nystagmus test in a case of neck fixation with a collar Without a collar

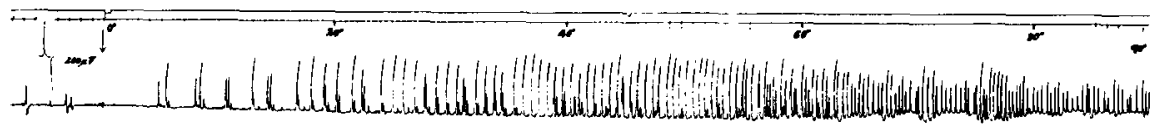

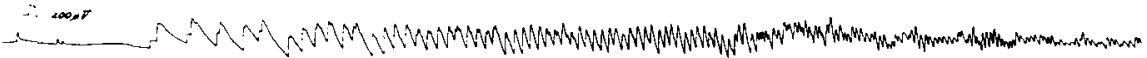
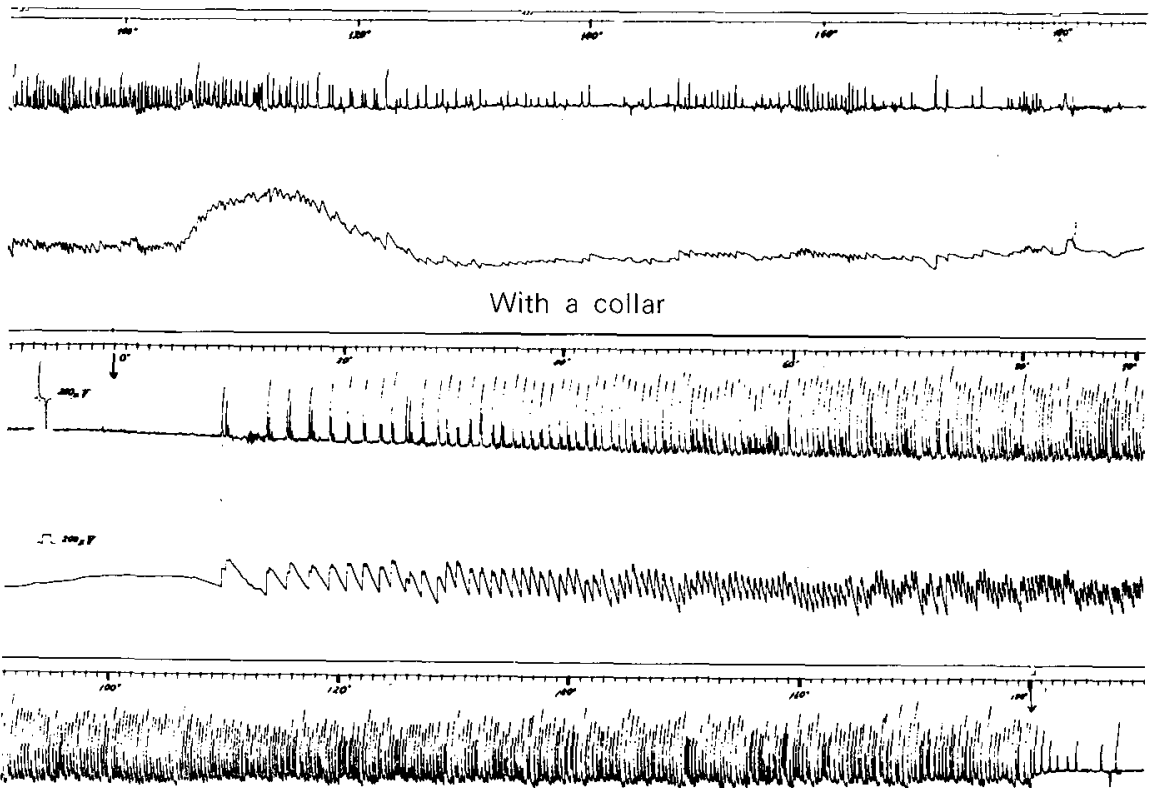

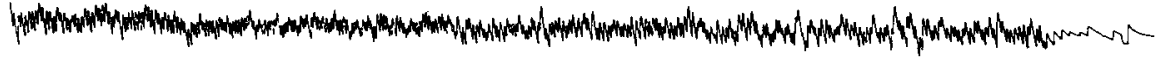

Fig. 4. Shows optic eye nystagmus of a 26 year old man with whiplash injury. Optic eye nystagmus occurs irregularly and inactively when no collar is worn. It improved on fixing the neck suitably with a collar. Namely, as shown in the lower part of this figure, optic eye nystagmus during neck fixation is far more regular and active than without neck fixation.

Equilibrium Res Suppl. I 
Case 4: A 26 year old man sustained a whiplash injury when his car hit a large rock. At the time of the accident he was aware of a crack in the neck. A few hours later nuchal pain and a sensation of swaying developed. X-rays of the cervical spine revealed a slight incongruence $\left(c_{3,4}\right)$ and loss of the normal cervical curve. When the neck of the subject was fixed with a collar, nuchal pain greatly decreased and the incongruence mentioned above disappeared. Furthermore, it should be emphasized here that fixation of the neck enabled the subject to respond well to rapid movements of vertical stripes of the light, to which he could not react accurately without the collar. As shown in Fig. 4, optic eye nystagmus during neck fixation was far more regular and active than without neck fixation.

(ii) Results obtained in 39 cases with whiplash injury

When at least one of the following 4 items was induced from the equilibrium tests mentioned above, the result was taken as positive: 1. Reduction or disappearance of disturbances of the righting reflex; 2. Reduction or disappearance of deviation in writing, or ataxic writing; 3. Increase in frequency and eye speed of optic eye nystagmus, and 4. Reduction or disappearance of stepwise, zigzag or irregular eye movements in eye tracking. Positive results were obtained in $27(69 \%)$ of the 39 cases examined. Of the remaining 12 cases, 9 showed no demonstrable changes in pre-existing disequilibrium, and 3 showed aggravation of disequilibrium.

(iii) Correlation between changes in X-rays of the cervical spine and those in equilibrium function on fixing the neck with a collar

In 22 vertigo cases with whiplash injury changes in the X-ray pictures of the cervical spine were observed on neck fixation and these changes were compared with changes in equilibrium function on neck fixation. From this comparison, as shown in Table 2, it was noted that cases who showed improvement of abnormality of the cervical spine on neck fixation did not show any sign of aggravation of pre-existing ataxia and indeed mostly showed improvement. Conversely, in patients who showed aggravation of the abnormality of the cervical spine on neck fixation there was no demonstrable improvement of ataxia. Furthermore, from these two examinations it was noted that pre-existing disequilibrium

Table 2. Correlation between changes in X-rays of the cervical spine and those in equilibrium function on fixing the neck with a collar

-Analysis of 22 cases with whiplash injury-

\begin{tabular}{ccccc}
\hline \multirow{2}{*}{ Equilibrium function } & \multicolumn{3}{c}{ X-rays of the cervical spine } \\
\cline { 2 - 5 } & $\begin{array}{c}1 \\
\text { Improved }\end{array}$ & Unchanged & Aggravated & Total \\
\hline Improved & $(78.5 \%)$ & $(21.5 \%)$ & $(0 \%)$ & $(100 \%)$ \\
\hline Unchanged & $\begin{array}{c}3 \\
(57.1 \%)\end{array}$ & $\begin{array}{c}2 \\
28.5 \%)\end{array}$ & $\begin{array}{c}1 \\
14.4 \%)\end{array}$ & $(100 \%)$ \\
\hline Aggravated & 0 & 0 & 1 & 7 \\
& $(0 \%)$ & $(0 \%)$ & $(100 \%)$ & $(100 \%)$ \\
\hline
\end{tabular}


Table 3. Correlation between results in equilibrium examinations by neck fixation with a collar and by anodic low-frequency pulse stimulation of the neck -Analysis of 19 cases with whiplash injury-

\begin{tabular}{|c|c|c|c|c|}
\hline 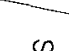 & & \multicolumn{2}{|c|}{ Collar } & \multirow{2}{*}{ Total } \\
\hline $\begin{array}{l}\frac{\bar{C}}{0} \\
\stackrel{\overline{0}}{\bar{O}} \\
\end{array}$ & Results & Improved & Aggravated & \\
\hline \multirow{2}{*}{ 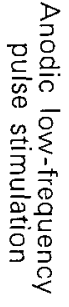 } & Improved & 2 & 1 & 3 \\
\hline & Aggravated & 13 & 3 & 16 \\
\hline \multicolumn{2}{|r|}{ Total } & 15 & 4 & 19 \\
\hline
\end{tabular}

was more easily improved in cases with lesions of the upper cervical spine $\left(c_{1}-c_{4}\right.$; upper type of cervical injury) than in those with lesions of the lower cervical spine $\left(c_{4}-c_{7}\right.$; lower type of cervical injury); that is that, in 8 out of the 12 cases with upper type of cervical injury pre-existing disequilibrium was improved by neck fixation, whereas in 2 out of the 5 cases with lower type of cervical injury the same tendency was noted. From the series of experiments mentioned above, it seems that hypertension of the cervical soft tissues, particularly that in the upper cervical region, is a cause of vertigo due to whiplash injury.

(C) Correlation between results of equilibrium tests with anodic low-frequency pulse stimulation of the neck and those of equilibrium tests on neck fixation

As shown in Table 3, most cases whose equilibrium function was decreased by anodic low-frequency pulse stimulation of the neck regained this function on wearing a collar. As previously mentioned, anodic low-frequency pulse stimulation would increase abnormal centripetal impulses from the injured cervical soft tissues, whereas wearing a collar would suppress these impulses. Therefore, the contrast between the results of these two tests suggests that vertigo in these cases is possibly caused by hypertension of the cervical soft tissues. This consideration is, of course, fully compatible with our conclusion mentioned above.

(D) Equilibrium tests with adrenaline loading

In cases with traumatic cervical vertigo, we have to consider not only disturbances of the cervical soft tissues, but also dysfunction of the central nervous system, especially the brain stem, since these vertigo cases often gave abnormal reactions in the optic eye nystagmus test and eye tracking test. To obtain further evidence of this, we developed the following type of equilibrium tests with adrenaline loading. Using cats anesthetized with cyclopropane, Porter showed that changes in the electrical activity can be induced

Equilibrium Res Suppl. 1 
in a small part of the hypothalamus near the mammillary body when adrenaline is injected intravenously (Porter ${ }^{35}$ 1952). In 1960, Malherbe reported the possibility of a direct effect of adrenaline on the hypothalamus (Malherbe ${ }^{29}$ 1960). Recently, Kawamura and Oshima confirmed that adrenaline directly acts on the posterior hypothalamus, influencing the electrical activity of the paleo-, and archicortex (Kawamura and Oshima ${ }^{24}$ 1962). According to several investigators, the hypothalamus is the locus for coordination of the autonomic nervous system, the endocrine nervous system and the somatic nervous system (Magoun et al. ${ }^{28}$ 1938, Anderson et al. ${ }^{1}$ 1956, Torii ${ }^{44}$ 1966). Therefore, if this area is stimulated in some way, such as through the administration of adrenaline, not only the function of the autonomic nervous system but also that of the somatic nervous system may be modified. Furthermore, Sturm and Fuss noted that cases with the posttraumatic syndrome, in whom dysfunction of the hypothalamo-brain stem often exists, tend to show abnormal sensitivity to adrenaline (Sturm ${ }^{39}$ 1948, Fuss ${ }^{12}$ 1953). It is widely believed that the posterior hyothalamus, through Schutz's longitudinal dorsal fascicle, is connected to the brain stem. The brain stem, through the reticulospinal tract, is then connected to the somatomotor cells in the columna ventralis, and further to the muscles of the trunk and the limbs (Brodal ${ }^{8}$ 1957). On the other hand, the MLF originating from the brain stem connects to the oculomotor nuclei, influencing the eye muscles. The MLF is also connected to the somatomotor cells in the columna ventralis, influencing the muscles of the trunk and the limbs. Therefore, it is possible that administration of adrenaline, in such a small amount that it will cause no marked reactions in normal subjects, may in vertigo cases with whiplash injury cause a demonstrable ataxia of the eyes, the trunk and the limbs through the descending pathways just mentioned. On the other hand, many results suggest that adrenaline acts primarily on the peripheral sympathetic nerves. According to Leak, it can be proved that the states elicited by adrenaline in the regions of the peripheral sympathetic nerves may be conveyed to the brain stem through feedback systems, effecting the activities of this part of the brain (Leak ${ }^{26}$ 1955). Furthermore, recent investigations of Bowman and Raper showed that adrenaline stimulates the activity of beta receptors in the denervated slow and fast contracting skeletal muscles, elevating the tonus of these muscles (Bowman and Raper ${ }^{6}$ 1967). It is generally accepted that in cases with whiplash injury there often are lesions of the deep nuchal muscles, which are slow contracting muscles. Accordingly, it is suggested that the beta receptors in the injured nuchal muscles may be functionally damaged and show over-activity. Thus, on injection of adrenaline they may show marked hypertension. On examination of the cortical EEG's of rabbits we found a close relationship between the tonus of neck muscles, especially the deep nuchal muscles and the activity of the reticular formation in the brain stem, and demonstrated that an excessive increase or reduction in the tonus of these muscles can cause dysfunction of the reticular formation in the brain stem (Hinoki et al. ${ }^{18} 1967$, Hinoki ${ }^{16}$ 1970). Thus, adrenaline acts on the brain stem, even though its primary action is on the injured nuchal muscles. Based on the reports hitherto made, we designed equilibrium tests with adrenaline loading to examine brain stem disorder as related vertigo 
due to cranio-cervical injury. In these equilibrium tests, we injected adrenaline subcutaneously at a dosage of $0.006 \mathrm{mg}$ per $\mathrm{kg}$ body weight, and examined the reactivities of the ocular and skeletal muscles before and 10 minutes after completion of the injection by various tests. We tested the righting reflex (Romberg test and Mann's test), arm drift reaction (the blindfolded vertical writing test) and oculomotor function (the optic eye nystagmus test and the eye tracking test).

(2) Results

(i) Results obtained in normal subjects: Thirty normal subjects examined by these tests showed neither vertigo nor the appearance of ataxia of the eyes and body.

(ii) Results obtained in vergtio cases with whiplash injury

(a) Representative cases

Case 5: A 37 year old woman who sustained a whiplash injury when her car was bumped from behind. At the time of the impact she was dazed for a few minutes. Immediate-

A list of letters in the blindfolded vertical writing test with adrenaline loading Before injection

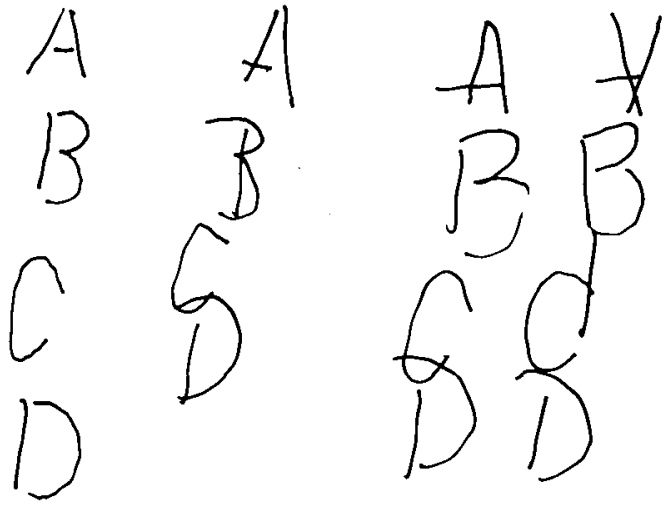

10 minutes after completion of injection

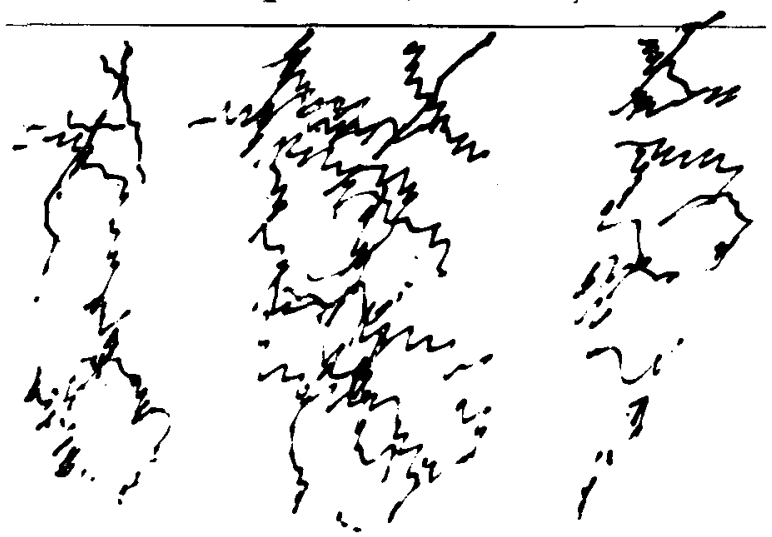

Fig. 5. Shows a list of letters written in the blindfolded vertical writing test by a 37 year old woman with whiplash injury. Letters before injection of adrenaline show left deviation with slight ataxic features. Ten minutes after completion of the injection, as shown in the lower part of this figure, her writing is markedly ataxic in the blindfolded verical writing test. 
ly after the accident she developed nuchal pain, headache and dizziness. These symptoms have continued for two years. X-ray photos of the neck showed no structural changes. Neurological examination revealed cerebellar ataxia, as indicated by dismetria and adiadochokinesis in both hands. She developed a very severe headache and sensation of falling when adrenaline was given. Five minutes after completion of the injection, tremor developed in the upper limbs and then it spread to the muscles of the whole body. This

Righting reflex with adrenaline loading

-Recordings of cephalograms and electromyograms in a case of Mann's testBefore injection

Cephalogram

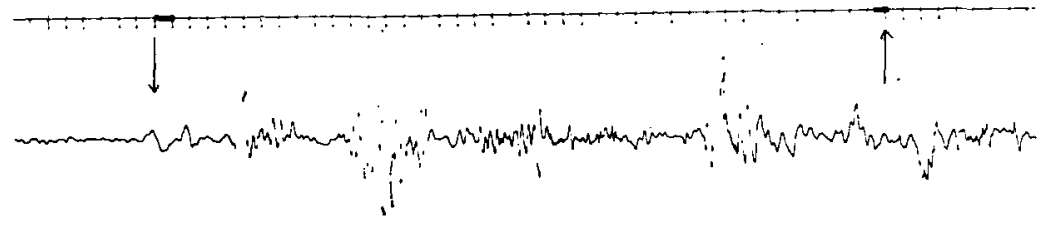

$\operatorname{EMG}($ R. neck)

$\mathrm{EMG}($ L. neck)

10 minutes after completion of injection

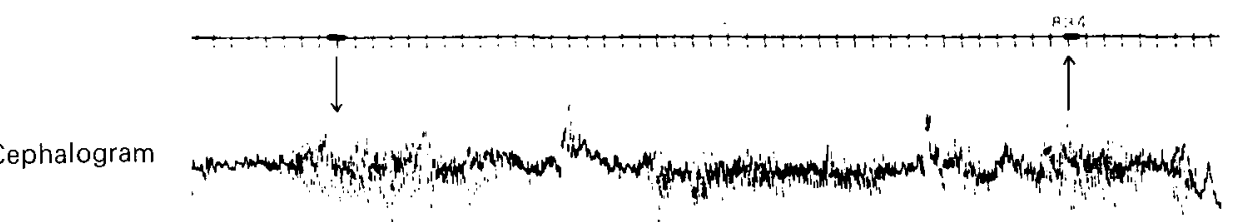

Cephalogram

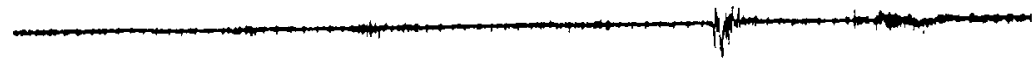

$\operatorname{EMG}($ R. neck)

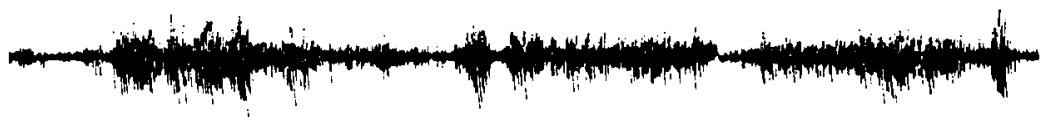

$\operatorname{EMG}($ L. neck)

Fig. 6. Shows cephalograms and EMG's from nuchal regions of a 32 year old woman who sustained a whiplash injury. The cephalogram is at the top of the figure and the EMG's of the right and left nuchal muscles are in the two lower rows in each figure. Before injection of adrenaline swaying of the head and abnormal EMG dicharges from the nuchal muscles are seen. Ten minutes after completion of the injection this tendency increases greatly, with marked increase in swaying of the head and abnormal EMG discharges as shown in the lower part of this figure. 
state, as shown in Fig. 5, was confirmed by her ataxic writing in the blindfolded vertical writing test.

Case 6: A 32 year old woman received a crack in the neck when her car struck an electric light pole. She was slightly dazed for about 5 minutes afterwards, but has had no memory defect since the accident. She complained of headache, dizziness, stiffness of the shoulders, lachrymation, emotional instability and palpitation, particularly associated with changes in the weather. X-rays of the cervical spine showed no demonstrable abnormality except a slight incongruence of the cervical vertebrae at the level of $c_{3,4}$ and $c_{4,5}$. She developed a sensation of falling associated with pallor, sweating and nausea when adrenaline was given. Increase in vertigo was evidenced as aggravation of preexisting ataxia (Fig. 6). Namely, 10 minutes after the injection there was a pronounced increase in swaying of the head in parallel with burst-like EMG discharges from the nuchal region.

Ocular movements in the eye tracking test with adrenaline loading

Before injection

Right eye

$\Omega 200 \mathrm{~N}$

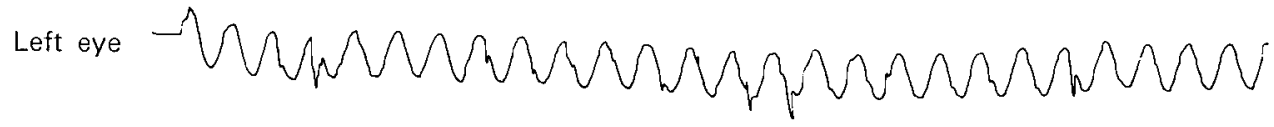

10 minutes after completion of injection

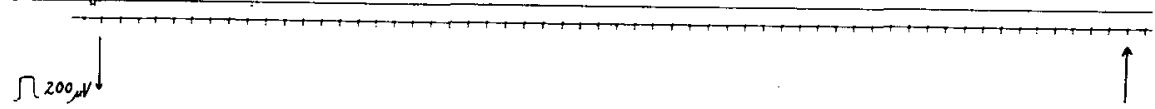

Right eye

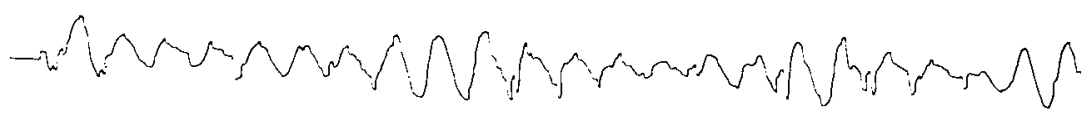

$\Omega_{200} \mathrm{~V}$

Left eye

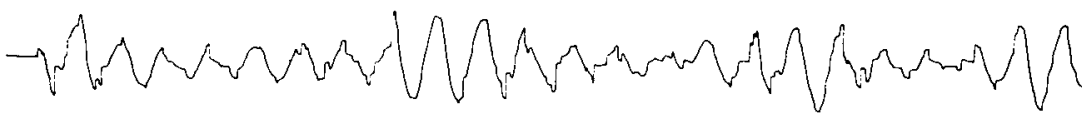

Fig. 7. Shows eye tracking curves of a 24 year old man who sustained a whiplash injury. Before injection of adrenaline he shows almost normal eye tracking curves, in which movements of the two eyes are synchronous and give essentially smooth sine curves, except for the occurrence of a few saccadic curves. Ten minutes after completion of the injection eye tracking function is greatly reduced, both eyes giving zigzag curves.

Equilibrium Res Suppl. 1 
Case 7: A 24 year old man sustained a whiplash injury when his car was struck from behind at a crossing while he was waiting for the lights to change. He has experienced no unconsciousness or memory defect since the accident. However, pain has developed in the neck associated with headache, head dullness, dizziness and slight lumbago. Xray examination revealed no abnormality except a slight incongruence of the cervical vertebrae at the level of $c_{3,4}$ and $c_{4,5}$. He complained of a pronounced increase in the sensation of falling and inability to follow a moving target when adrenaline was given. His complaints were endorsed by aggravation of eye tracking function. Namely, as shown in Fig. 7, before adrenaline injection he showed almost normal eye tracking curves, in which movements of both eyes were synchronous and gave essentially smooth sine curves except for the occurrence of a few zigzag curves. However, 10 minutes after completion of adrenaline injection saccadic and stepwise eye tracking curves appeared, which, of course, indicated aggravation of latent dysfunction of the oculomotor system.

This series of examinations shows that dysfunction of the hypothalamo-brain stem often exists in cases of vertigo due to whiplash injury. This consideration is, we feel, compatible with the well known facts that ataxic writing in the blindfolded vertical writing test and saccadic and stepwise eye movements in the eye tracking test frequently appear in patients suffering from disturbances of the brain stem as well as the cerebellum.

(b) Results obtained in $\mathbf{5 0}$ vertigo cases with whiplash injury

When at least one of the following 4 items was induced from equilibrium tests with adrenaline loading, the result was taken as positive: 1. The appearance or intensification of deviation in writing, or ataxic writing; 2 . The appearance or intensification of disturbances of the righting reflex; 3. Marked inhibition or abnormal facilitation of optic eye nystagmus or the appearance of abnormal optic eye nystagmus, as indicated by the inversion phenomenon; and 4. The appearance or intensification of abnormal eye tracking curves, as indicated by zigzag, stepwise or irregular curves. Positive results were obtained in 41 of the 50 vertigo cases examined. Of the remaining cases, 9 showed no demonstrable changes. Incidentally, only 3 out of 30 cases with vertigo of peripheral vestibular origin gave a positive result in these tests. However, these 3 cases giving a positive result showed no sign of ataxia of central origin such as abnormal optic eye nystagmus, derangement of eye tracking curves or ataxic writing, but usually only an increase in the degree of deviation in writing. In contrast to this, vertigo cases with cranial injury often showed similar results to those of vertigo with whiplash injury.

\section{COMMENT}

A series of examinations showed that in most vertigo cases with whiplash injury there were both hypertension of the cervical soft tissues and dysfunction of the hypothalamobrain stem. However, systematic studies have not been made on the relationship of these two factors in causing disequilibrium and vertigo in cases of whiplash injury. The following facts seem to give some evidences of this problem.

(i) When procaine solution, known to interrupt the activity of gamma fibers, was 
injected into the deep group of the nuchal muscles of a normal subject, the subject developed vertigo, as indicated by a sensation of falling or black-out, without cochlear symptoms. In this condition, the subject showed not only body ataxia but also dysfunction of the oculomotor system, which was evidenced as a lack of coordination between head and eye movements during active head rotation. In our clinical experience, this loss of coordination is greatest and most frequent in cases with brain stem disorder (Hinoki and Kurosawa $^{17}$ 1964). Furthermore, it was reported by Campbell and Parsons that the deep nuchal muscles are important in determining the position of the head, the trunk and the limbs in coordination with eye movments when the eyes follow a moving object, and that the center coordinating these movements may be in the brain stem reticular formation and the MLF (Campbell and Parsons ${ }^{10}$ 1944). Based on the report of Campbell and Parsons, it seems likely that sudden blockage of the activity of the deep nuchal muscles by procaine might produce dysfunction of the brain stem, resulting in vertigo and ataxia without cochlear symptoms.

(ii) We have already reported that when procaine solution was injected into the deep nuchal muscles of guinea pigs, development of optic head and eye nystagmus was strongly inhibited (Hinoki and Terayama ${ }^{19}$ 1966). Many investigators have reported that inhibition of optic eye nystagmus was greatest and most frequent in cases where the function of the brain stem reticular formation was disturbed. From previous reports, it is concluded that marked inhibition of optic head and eye nystagmus in the above mentioned guinea pigs is due to dysfunction of the brain stem reticular formation. This conclusion is supported by the following facts. When the deep nuchal muscles of rabbits are treated with procaine, both the arousal EEG reaction to optic stimulation and optic eye nystagmus are strongly inhibited. However, when the superficial nuchal muscles of rabbits are treated with procaine, there is no demonstrable inhibition of the arousal EEG reaction or nystagmus (Hinoki et al. ${ }^{18}$ 1967). The arousal reaction in the EEG is closely related to the activity of the brain stem, especially the ascending activating system (Rheinberger and Jasper $^{36}$ 1937, Moruzzi and Magoun ${ }^{31}$ 1949). These workers found that animals did not show any detectable arousal EEG reaction to sensory stimulation when function of the brain stem was disturbed, but the classical sensory paths remained intact. Thus, sudden blockage of the acitivity of the cervical proprioceptors may well cause functional impairment of the brain stem, especially the ascending activating system.

(iii) When an adequate electric stimulation (e.g., $10 \mathrm{msec} ., 1 \mathrm{v}$ pulse stimulation for 90 seconds) was applied to the deep nuchal muscles of normal rabbits, the animals tended to develop very active optic eye nystagmus. Conversely, on stronger stimulation (e.g., $10 \mathrm{msec} ., 15 \mathrm{v}$ pulse stimulation for 180 seconds) of the same muscles, the animals usually showed marked inhibition of optic eye nystagmus or, in some cases, abnormal optic eye nystagmus, as indicated by the inversion phenomenon (Hinoki ${ }^{16}$ 1970). Furthermore, our experiments on rabbits showed that the former weak pulse stimulation tended to produce desynchronized waves in the EEG, whereas the latter strong pulse stimulation evoked slow waves or a sleep pattern in the EEG (Hinoki ${ }^{16}$ 1970). In addition to these facts, 
Ishida et al. reported that daily application of pulse stimulation to the neck often produced demonstrable changes in optic eye nystagmus. Namely, daily application of a weak pulse stimulus tended to induce "response increase in optic eye nystagmus," whereas daily application of a strong pulse stimulus tended to cause "response decline in optic eye nystagmus," or in some cases, "the inversion phenomenon of optic eye nystagmus" (Ishida et al. ${ }^{22}$ 1968). Incidentally, in rabbits in which the deep nuchal muscles were treated with procaine, repetition of electrical (pulse) stimulation to the neck did not induce either an increase or a decline in optic eye nystagmus. These findings indicate that repetition of abnormal centripetal impulses from the injured cervical soft tissues, especially the deep group of nuchal muscles, can act on the brain stem to establish a stable dysfunction of this part of the brain. This, of course, is very important in speculating on mechanisms of vertigo in human subjects with whiplash injury.

From clinical observations on traumatized patients and from the experimental results just mentioned, the mechanisms of vertigo due to whiplash injury may be explained as follows: Abnormal centripetal impulses arising from the injured cervical soft tissues may ascend repeatedly along the paths described below. These reach the brain stem and then the hypothalamus, making dysfunction of these parts of the brain manifest. The dysfunction of these parts of the brain may project to the muscles of the eyes, the trunk, and the limbs through the descending paths described below causing disability or ataxia in these organs. Thus, vertigo is possibly induced by this ataxia or disability. Among the neural elements involved in producing vertigo of this type, the following paths seem important. Among the ascending paths from the cervical proprioceptors to the brain stem, the spinoreticular tract is, we feel, the most important since most fibers of this tract ascend along the lateral fascicle and the anterior column and terminate in the reticular formation both of the medulla oblongata and the pons (Brodal ${ }^{8}$ 1957, Nauta and Kuypers ${ }^{32}$ 1958, Bowsher $^{7}$ 1965). However, some fibers of this tract ascend directly to the mid brain, connecting to Deiters' nucleus (Terada ${ }^{41}$ 1960, Niimi et al. ${ }^{33}$ 1968). Furthermore, this tract changes neurons in the medulla oblongata, the pons and the mid brain, and terminates in the superior colliculus (Nauta and Kuypers ${ }^{32}$ 1958). It is generally accepted that the reticular formation of these parts of the brain, as well as Deiters' nucleus and the superior colliculus, is potent in producing both ocular and spinal reflexes related to body equilibrium. Among the descending paths from the brain stem, the MLF is important in vertigo cases because this tract is believed to play a major role in producing nystagmus. This tract originates in the brain stem and connects to both the oculomotor nuclei and the somatomotor cells in the columna ventralis (Buchanan ${ }^{\circ}$ 1937). The reticulospinal tract also originates in the brain stem reticular formation of both medulla oblongata and the pons and connects to the somatomotor cells in the columna ventralis (Brodal ${ }^{8}$ 1957). This tract is thought to have a close relationship with the spinoreticular tract mentioned above. Thus, the MLF and the reticulospinal tract seem specially important with regard to disequilibrium due to whiplash injury. The brain stem is connected to hypothalamus by Schutz's longitudinal dorsal fascicle and the medial forebrain bundle. Among these 
fibers, Schutz's longitudinal dorsal fascicle is, we feel, the most important in producing vertigo due to whiplash injury; for most of our vertigo cases with whiplash injury showed hypersensitivity to adrenaline, indicating the appearance or aggravation of ataxia of central origin. The question then arises as to the role of the cerebellum in producing vertigo due to whiplash injury because the cerebellum is an important part of the brain which is closely connected to the proprioceptors in the cervical region, and this part of the brain also an intimate relationship with the brain stem. In our clinical observations, some cerebellar ataxia was seen in vertigo cases with whiplash injury; i.e., a positive supporting reflex ( 5 out of 25 cases), ataxic writing suggestive of cerebellar disorder ( 2 out of 25 cases) and dismetria or asynergia (hypo-, and adiadochokinesis) of the upper limbs ( 7 out of 25 cases). It is worth noting that 3 out of 7 cases with cerebellar ataxia showed appreciable improvement of ataxia when the neck was fixed with a collar (Hine et al. ${ }^{14}$ 1968). This finding, we feel, suggests that abnormal centripetal impulses from the injured cervical soft tissues affect the cerebellum via the ascending paths below described making dysfunction of this part of the brain manifest. Naturally this dysfunction of the cerebellum may participate in producing vertigo due to whiplash injury. With regard to the neural elements involved in this type of vertigo, especially the ones connecting the cervical proprioceptors to the cerebellum, the spinocerebellar tract, the spino-olivary tract and the olivo-cerebellar tract seem important. However, in our clinical observations mentioned above, neural mechanisms via the cerebellum seem to be of rather minor importance in formation of vertigo due to whiplash injury. We proposed the scheme shown in Fig. 8 based on the neural elements mentioned above as the mechanisms of vertigo due to whiplash injury. From this scheme reasonable treatments of vertigo of this type can be deduced." Thus, one treatment is to correct functional dis-

Neural Mechanisms of Vertigo due to Whiplash Injury

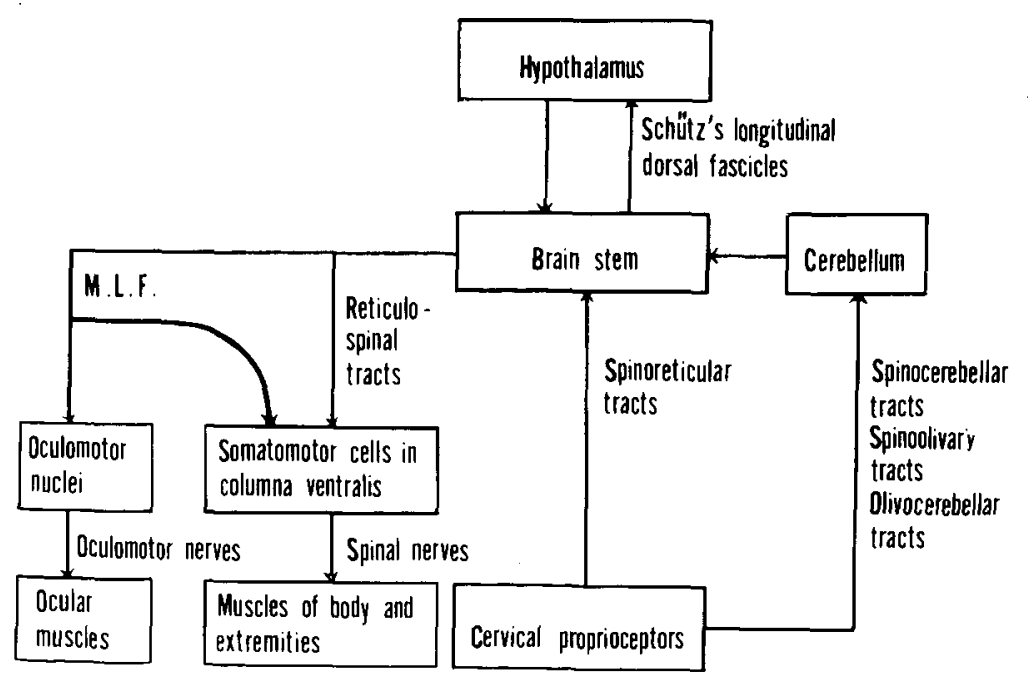

Fig. 8.

Equilibrium Res Suppl. I 
orders of the cervical soft tissues and so block abnormal centripetal impulses from the injured cervical soft tissues. Procedures for the first treatment include procaine infiltration into the tender areas of cervical soft tissues, low-frequency pulse stimulation of the neck (placing the cathode on the painful area) and paraffine packing around the neck. A case of whiplash injury treated by paraffine packing around the neck is described below.

Case 8: A 52 year old man sustained a whiplash injury when his car was bumped from the rear. Since the accident, he has suffered from headache, vertigo and tenderness of the neck and shoulders. This patient received various physical and medical treatments without apparent beneficial effect before application of paraffine packing around the neck, However, after the paraffine packing around the neck vertigo and tenderness of the neck and shoulders decreased appreciably. This was confirmed by improvement of eye tracking function, as shown in Fig. 9, although some abnormalities of eye tracking function remained, as indicated by zigzag and stepwise curves.

Some investigators have reported that cervical traction is an effective treatment for vertigo due to cervical trauma. However, when this treatment is done soon after the acci-

Effects of paraffine packing around the neck on vertigo due to whiplash injury

Before treatment
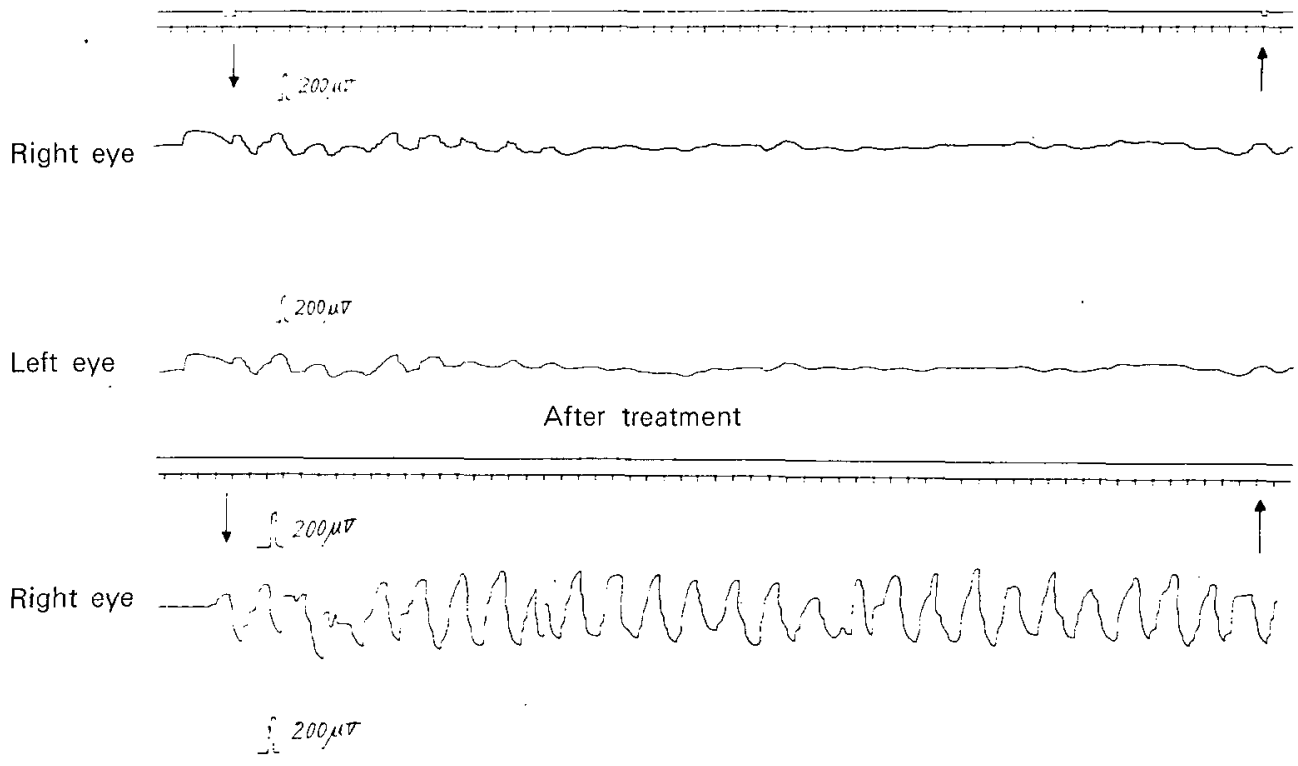

Left eye

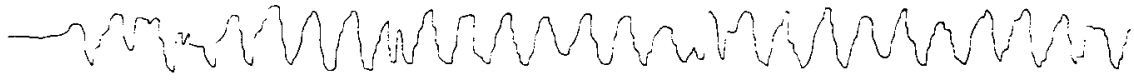

Fig. 9. Shows eye tracking curves of a 52 year old man who sustained a whiplash injury. Before application of paraffine packing around the neck he shows marked reduction in eye tracking function; which is evidenced by very irregular and inactive-type eye tracking curves. After completion of this treatment eye tracking function improves considerably, as shown in the lower part of this figure, although some abnormalites of eye tracking function remain, as indicated by zigzag and stepwise curves. 
dent, vertigo often appears or is aggravated. A case with whiplash injury treated by cervical traction is described below.

Case 9: A 21 year old man sustained a whiplash injury when his car was struck by another vehicle from behind. After the accident he developed a sensation of falling and

Effect of cervical traction on vertigo due to whiplash injury Before cervical traction

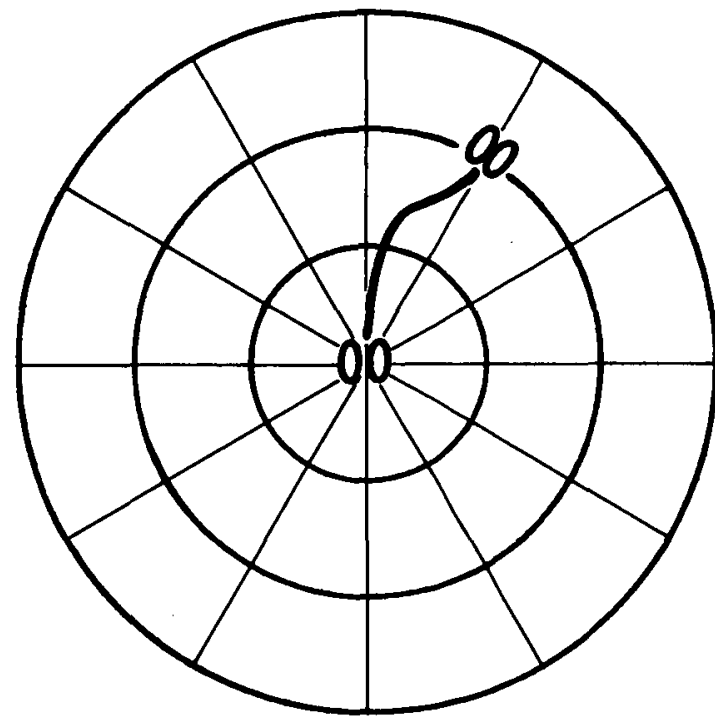

After cervical traction 4 times

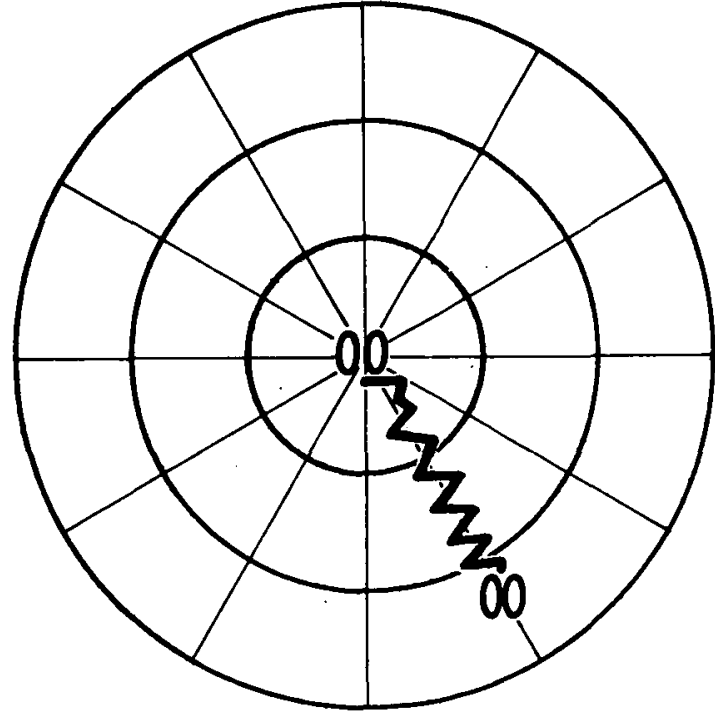

Fig. 10. Shows a locus in the stepping test of a 21 year old man with whiplash injury. Before cervical traction he shows right deviation and forward displacement without notable ataxia in the stepping test. After repetition of cervical traction 4 times, as shown in the lower part of, this figure, he demonstrates right deviation and backward displacement with marked ataxia.

Equilibrium Res Supp/. I 
pain of the neck and shoulders. After repetition of cervical traction 4 times he developed an increased sensation of falling, especially of falling backwards. This complaint was endorsed, as shown in Fig. 10, by observation of backward displacement with ataxia in the stepping test. Incidentally, he also showed a marked inhibition of optic eye nystagmus at this time.

The results seen in case 8 and 9 are, we feel, very interesting for the following reason. In these two cases no other treatments were given in the observation period, and yet the results suggest significant changes in the function of the brain stem, i.e., recovery of function in case 8 and aggravation of symptoms in case 9 . These results seem fully compatible with our previous consideration that dysfunction of the brain stem is caused, not only by traumatizing force at the time of accident, but also secondarily by disturbances of the cervical soft tissues.

The second method of treatment includes administration of P-chlorophenoxyacetic acid dimenthyl aminoethyl ester (Lucidril, Centrophenoxine) or C.D.P.-choline (Nicholin). These drugs are considered to restore impaired function of the hypothalamo-brain stem. A case of whiplash injury treated by administration of Centrophenoxine is described below.

Effects of Centrophenoxine on vertigo to whiplash injury Before administration

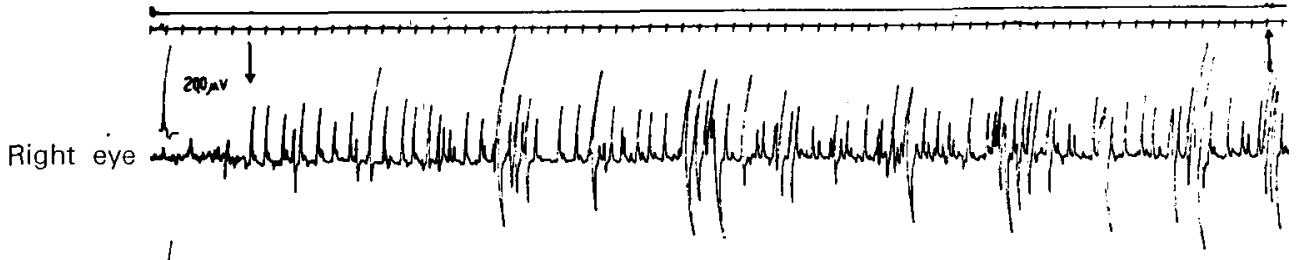

Left eye<smiles>I[I-]</smiles>

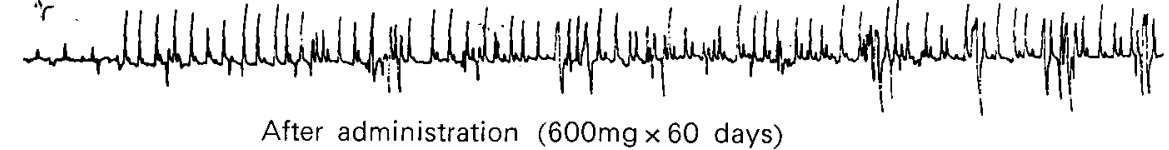

After administration $(600 \mathrm{mg} \times 60$ days $)$

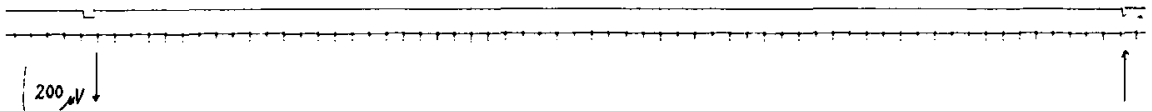

Right eye $\lfloor 200 \mathrm{~V}$

Left eye

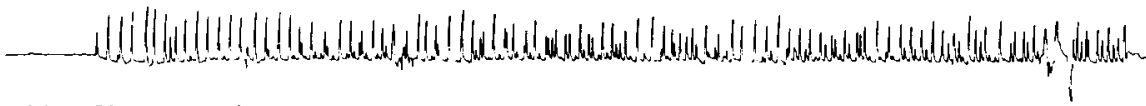

Fig. 11. Shows optic eye nystagmus of a 47 year old man who incurred a whiplash injury. Before administration of Centrophenoxine his optic eye nystagmus is irregular and inactive. After administration of the drug $600 \mathrm{mg}$ per day for 60 days) function of the oculomotor system improves greatly, optic eye nystagmus becoming regular and active. 
Case 10: A 47 year old man sustained a whiplash injury when his car was bumped from the rear. At the time of the accident he lost consciousness for a few minutes. Since the accident he has suffered from a sensation of falling, tenderness of the neck and emotional instability. After administration of Centrophenoxine these symptoms were much reduced, especially the sensation of falling. As shown in Fig. 11, improvement was also confirmed by the active and regular appearance of optic eye nystagmus.

This case is very interesting in connection with speculation on the mechanisms of vertigo due to whiplash injury, for the appearance of optic eye nystagmus is noted to have a close relationship with the activity of the brain stem; and in addition, Centrophenoxine is reported to be effective in restoring impaired function of the hypothalamobrain stem. In other words, the findings on case 10 indicate that dysfunction of the hypothalamo-brain stem often exists in cases of vertigo due to whiplash injury. Incidentally, the drugs mentioned above were effective for patients who showed dysfunction of the hypothalamo-brain stem before treatment but were ineffective or, in some cases, rather injurious for patients who showed no demonstrable signs of dysfunction of these parts of the brain (Ushio et al. ${ }^{45}$ 1968). To test for possible dysfunction of the hypothalamo-brain stem, we employed the ocular function tests (the optic eye nystagmus test and the eye tracking test) and the equilibrium tests with adrenaline loading mentioned above. Thus, at present these drugs are only administered to patients with positive signs of hypothalamo-brain stem dysfunction.

\section{SUMMARY}

To see whether hypertension of the cervical soft tissues participates in producing vertigo due to whiplash injury, we developed two types of equilibrium tests: equilibrium tests with anodic low-frequency pulse stimulation of the neck and equilibrium tests after fixing the neck with a collar. Disequilibrium due to whiplash injury was often aggravated by pulse stimulation, whereas it tended to decrease or disappear on fixing the neck with a collar. These findings indicate that hypertension of the cervical soft tissues is often an important factor in the development of vertigo due to whiplash injury.

To investigate the possible existence of hypothalamo-brain stem dysfunction in vertigo cases with whiplash injury, we carried out equilibrium tests with adrenaline loading. These tests showed that in most cases with vertigo, ataxia appeared or was intensified by adrenaline loading. We concluded that hypothalamo-brain stem dysfunction is a possible etiologic factor in the development of vertigo due to whiplash injury. From these observations it seemed that vertigo due to whiplash injury develops because abnormal centripetal impulses arising from the injured cervical soft tissues reach the hypothalamo-brain stem cause manifestation of dysfunction in these parts of the brain. Thus, marked ataxia of the eyes and body might result, which would lead to vertigo in these cases.

Therefore, treatment for this kind of vertigo should be directed to improve impaired function both (i) in the cervical region and (ii) in the hypothalamo-brain stem system. 


\section{ACKNOWLEDGEMENTS}

The authors are greatly indebted to Prof. K. Niimi (Department of Anatomy, Okayama University) and Dr. M. Noshima (Department of Orthopedic Surgery, Tokushima University) for their valuable advice regarding various problems on fiber connections of the central nervous system and on X-ray photos of the cervical spine. Grateful acknowledgement is made to co-workers in the ENT Department of Tokushima University and Iwate Medical University for their assistance and helpful discussion.

\section{REFERENCES}

1) Anderson, B., Grant, R., \& Larrson, S.: Central control of heat loss mechanism in the goat. Acta Physiol. Scand. $37: 261-280,1956$.

2) Barré, J. A.: Sur un syndrome sympathique cervical posterieure et sa cuase fréquente; 1'arthrite cervicale. Rev. Neurol. $45: 1246,1926$. Cit. by Sandström, J.: Cervical syndrome with vestibular symptoms. Acta otolaryng. (Stockholm) $54: 207-226,1961$.

3) Bärtschi-Rochaix, W.: Migraine cervicale. H. Huber Verlag. Berne, 1948. Cit. by Ishii, S. et al.: Clinical observations on vertigo of cervical origin. Surg. Therap. (Tokyo) $6: 393-$ 402, 1962.

4) Biemond, A.: Thrombosis of basilar artery and the vascularization of the brain stem. Brain, $74: 300-317,1951$.

5) Bos, J. H.: On vestibular nystagmus without causative endolymph displacement. Acad. Profeschr. (University of Amsterdam) Cloeck En Moedigh, N. V., Amsterdam, 1962. pp. 41-47.

6) Bowman, W. C., \& Raper, G.: Adrenotropic receptors in skeletal muscles. Ann. New York Acad. Sci. 139 : 741-753, 1967.

7) Bowsher, D.: The anatomophysiological basis of somatosensory discrimination. Int. Rev. Neurobiol. $8: 35-75,1965$.

8) BRodaL, A.: The reticular formation of the brain stem. Edinburgh, publishers Oliver and Boyd, 1957. pp. 1-87.

9) Buchanan, A. R.: The course of the secondary vestibular fibers in the cat. J. Comp. Neurol., 67: 183-204, 1937.

10) Campbell, D. G., \& Parsons, C. M.: Referred head pain and its concomitants. J. Nerv. Ment. Dis. 99 : 544-551, 1944

11) COPE, S., \& Ryan, G. M. S.: Cervical and otolith vertigo. J. Laryng. $73: 113-119,1959$.

12) Fuss, H.: Über vegetative Regulationen bei commotio cerebri und anderen Unfällen. Langenbeck's Arch. Klin. Chir, u. Dtsch. Zschr. Chir. $274:$ 452-464, 1953.

13) Gray, L. P.: Extra labyrinthine vertigo due to cervical muscle lesions. J. Laryng. $70: 352-$ $361,1956$.

14) Hine, S., Hinoki, M., OKada, S., TAda, Y.: Cerebellar ataxia caused by whiplash trauma. The 69th Meeting of Pract. Otol. (Kyoto) 1968.

15) HINOKI, M.: Oto-neurological observations on whiplash injuries to neck with special reference to the formation of equilibrial disorder. Clin. Surg. (Tokyo) 22: 1683-1690, 1967.

16) HiNoKi, M.: Physioliogical role of cervical proprioceptors in the development of optic and vestibular reflexes. Adv. Neurol. Sci. (Tokyo) $14: 134-139,1970$. 
17) Hinoki, M., \& Kurosawa, T.: Note on vertigo of cervical-origin. Pract. Otol. (Kyoto) $57: 10-20,1964$.

18) Hinoki, M., Sawada, K., \& Kondo, M.: Experimental studies on the mechanism of vertigo of cervical-origin. Prac. Otol. (Kyoto) 60 (suppl. 1) : 27-37, 1967.

19) Hinoki, M., \& Terayama, K.: Physiological role of neck muscles in the occurrence of optic eye nystagmus. Acta otolaryng. (Stockholm) $62: 157-169,1966$.

20) Hinoki, M., Terayama, K., Miyauchi, Y., Noguchi, G., \& Nakamura, H.: Studies on posttraumatic vertigo. Pract. Otol. (Kyoto) 60 (suppl. 1) : 14-26, 1967.

21) IKEDA, K., \& Kobayashi, T.: Experimental studies on whiplash trauma. Clin. Surg. (Tokyo) $22: 1655-1659,1967$.

22) Ishida, Y., Hinoki, M., Hine, S., \& OKadA, S.: Correlation between the cervical proprioceptors and the oculomotor system in regard to body equilibrium. The 22nd Meeting of Jap. Soc. Equilibrium Res. 1968.

23) Ishit, S., TANI, Y., Konod, Y., \& WAGA, S.: Clinical observations on vertigo of cervicalorigin. Surg. Therap. (Tokyo) $6: 393-402,1962$.

24) Kawamura, H., \& Oshima, K.: Effect of adrenaline on the hypothalamic activating system. Jap. J. Physiol. $12:$ 225-233, 1962.

25) de KLeYn, A.: Über verschiedene Formen von Meniere's Syndrome. Disch. Zschr. Nervenh. 132 : 157-189, 1933.

26) LEAK, C. D.: 1955. Cit. by French, J. D.: The reticular formation, Handbook of physiology, sect. 1, Neurophysiology, 2, Am. Physiol. Soc. Washington. D.C., 1960. pp. 1281-1305.

27) Lieou, Y. C.: Syndrome sympathique cervical posterieur et arthrite cervicale chronique. These de Strasbourg., 1928, Cit. by Sandström, J.: Cervical syndrome with vestibular symptoms. Acta. otolaryng. (Stockholm) $54: 207-226,1961$.

28) Magoun, H. W., Harrison, F., Brobeck, J. R., \& Ranson, S. W.: Activation of heat loss mechanisms by local heating of brain. J. Neurophysiol. 1 : 101-114, 1938.

29) Malmerbe, W. H.: The passage of catechol amines through the bood brain barrier. Adrenergic mechanisms, 42. Cit. by Kawamura, H., \& Oshima, K.: Effect of adrenaline on the hypothalamic activating system. Jap. J. Physiol. $12: 225-233,1962$.

30) MASPETIOL, R.: Les troubles cochléo-vestibulaires par arthrose cervicale et leurs traitments. Otolaryngology (Tokyo) 32 : 939-994, 1960.

31) Moruzzi, G., \& Magoun, H. W.: Brain stem reticular formation and activation of the EEG. EEG. Clin. Neurophysiol. 1 : 455-473, 1949.

32) NAUTA, W.J.H., \& KuYPERs, H.G.J.M.: Some ascending pathways in the brain stem reticular formation. International symposium; Reticular formation of the brain (Henry Ford Hosp.), Little Brown and Co., Boston, 1958. pp. 3-30.

33) Nimi, K., Fujita, S., Abe, K., \& Kawamura, S.: An experimental-anatomical study on the spinothalamic tract in the cat. Okajima, Fol. Anat. Jap. $44: 255-283,1968$.

34) Philipszoon, A. J.: Compensatory eye movements and nystagmus provioked by stmulation of the vestibular organ and the cervical nerve roots. Pract. Oto-Rhino-Laryng. (Basel) 24 : 193-202, 1962.

35) Porter, R. W.: Alterations in electrical activity of the hypothalamus induced by stress stimuli. Am. J. Physiol. $169: 629-632,1952$.

36) Rheinberger, M. B., \& JASPER, H. H.: Electrical activity of the cerebral cortex in unanes- 
thetized cat. Am. J. Physiol. $119:$ 186-196, 1937.

37) SANDSTRöm, J.: Cervical syndrome with vestibular symptoms. Acta otolaryng. (Stockholm) 54 : 207-226, 1961.

38) Schneider, R. C., \& Crosby, E. C.: Vascular insufficiency of brain stem and spinal cord in spinal trauma. Neurology $9: 643-656,1959$.

39) Sturm, A.: Gedanken zur vegetativ-nervösen Problematik. Dtsch. Med. Wschr. 73 : 589 592, 1948.

40) Suzukı, M.: The effect of electricity of flowing electrode. J. Physiol. Soc. Jap. $17: 223-$ 234, 1955.

41) Terada, S.: Course \& termination of the long ascending spinal tracts and of the medial leminiscus in cats, with the special reference to the relation of these tracts to the reticular formation. J. Chiba Med. Soc. 36 : 1065-1075, 1960.

42) Tissington-Tatlow, W. F., \& Bammer, H. G.: Syndrome of vertebral artery compression. Neurology $7: 331-340,1957$.

43) Tokita, T.: Background of Meniere's disease. Pract. Otol. (Kyoto) 58 : 190-205, 1965.

44) ToRII, S.: Neural mechanisms of the autonomic nervous system. Physiology of the brain, Asakura Shoten Ltd., Tokyo, 1966. pp. 276-278.

45) Ushio, N., Hinoki, M., \& TAda, Y.: Clinical observations on effect of hypothalamobrain stem activating drugs on vertigo due to cranio-cervical injury. The 35th Meeting of ENT Soc. Jap. (Section of Shikoku) 1968.

46) Weeks, V. C., \& Travell, J.: Postural vertigo due to trigger area in the sternocleidomastoid muscles. J. Ped. $47:$ 315-326, 1955.

(Received February 11, 1971) 